\title{
DIVERSIDADE CULTURAL E LIVRE-COMÉRCIO: ANTAGONISMO OU OPORTUNIDADE?
}

\section{CULTURAL DIVERSITY AND FREE-TRADE: OPPOSICION OR OPPORTUNITY?}

\author{
DIVERSIDAD CULTURAL Y LIBRE COMERCIO: ¿ANTAGONISMO U \\ OPORTUNIDAD?
}

Vera Cíntia Álvarez ${ }^{1}$

\begin{abstract}
RESUMO:
Desde o início do século XX há um grande debate acerca da definição e do tratamento dos bens culturais expresso, principalmente, na oposição entre os adeptos da "Exceção Cultural" e do "Livre câmbio". Intensificado nos anos 90, com o processo de globalização, tal disputa envolveu uma gama de países distintos com posições e interesses conflitantes. O objetivo desse artigo é perceber o desenvolvimento histórico desse embate destacando a inserção, o modo de participação e as possíveis formas de intervenção do Brasil.
\end{abstract}

Palavras-chave: Globalização; Diversidade cultural; Livre-comércio; Bens culturais.

\section{ABSTRACT:}

Since the beginning of the 19th century, there is a discussion on the definition and the way that the cultural assets are treated. This discussion is expressed mainly in the opposition between the "Cultural Exception" and the "Free Exchange" followers. In the 90s, with the globalization, this discussion involved many countries which had different positions and interests. The purpose of this article is to notice the historical development of this discussion and the ways that Brazil might participate and intervene in it.

Key-words: Globalization; Cultural diversity; Free-trade; Cultural assets.

\section{RESUMEN:}

Desde el inicio del siglo XX existe un gran debate a cerca de la definición y del tratamiento de los bienes culturales que se expresa principalmente en la oposición entre los adeptos de la "Excepción Cultural" y del "Libre cambio". Intensificada en los años 90, con el proceso de globalización, tal disputa envolvió distintos países con interés y posiciones en conflicto. El objetivo de este artículo es percibir el desarrollo

\footnotetext{
${ }^{1}$ Ministra do Ministério das Relações Exteriores (MRE) da Coordenação-Geral de Intercâmbio e Cooperação Esportiva (CGCE). Prestou o exame para a carreira diplomática em 1981 e cursou o Instituto Rio Branco de 1982 a 1983. Nomeada terceira secretária, fez seu primeiro serviço provisório na Embaixada do Brasil na Indonésia. Serviu nas Embaixadas do Brasil em Pequim, Dublin e Tóquio, foi Cônsul-Geral adjunta em Roma de 1991 a 1994. No retorno de Tóquio, em fins de 2007, já promovida a ministra da carreira diplomática, recebeu a incumbência de erguer uma nova unidade no Itamaraty, a Coordenação-Geral de Intercâmbio e Cooperação Esportiva, para promover o esporte como instrumento de diplomacia e desenvolvimento. E-mail: veracintia@gmail.com

R. Inter. Interdisc. INTERthesis, Florianópolis, v.6, n.1, p. 254-278, jan./jul. 2009
} 
histórico de este embate destacando ahí el modo de participación y las formas posibles de intervención del Brasil.

Palabras-clave: Globalización; Diversidad cultural; Libre comercio; Bienes culturales.

Ao escolher mais uma vez defender Hollywood e ao invés de juntar-se ao consenso internacional, os Estados Unidos ficaram quase que completamente isolados na UNESCO quando da aprovação do novo instrumento internacional sobre cultura, a "Convenção sobre a Proteção e a Promoção da Diversidade das Expressões Culturais", aprovada com 148 votos a favor, 2 contra (Estados Unidos e Israel) e 4 abstenções (Austrália, Honduras, Nicarágua e Libéria), em 20 de outubro de 2005.

O novo instrumento internacional de cunho normativo e referencial foi percebido como necessário pela comunidade de países reunidos na UNESCO a fim de que a conflituosa interface entre comércio e cultura recebesse tratamento de um ponto de vista que procurasse equacionar positivamente a complexa relação entre o processo de globalização e a defesa das identidades culturais. O instrumento foi concebido para fornecer um arsenal de princípios e definições àqueles países que desejam evitar que os compromissos internacionais engendrados pela interdependência comercial, política e econômica contemporânea e as contradições do processo de globalização reduzam sua margem de flexibilidade para implementar políticas de promoção cultural interna. O processo de globalização intensifica as pressões de concorrência nos mercados internacionais e faz avançar a sociedade da informação, da imagem, do som e da mensagem, impulsionadas pela constante renovação e sofisticação da tecnologia. Consolidam-se os processos produtivos baseados na agregação de valor. As exportações de Serviços tornam-se o foco mais importante da luta por novos mercados. Cresce a permeabilidade das fronteiras nacionais à circulação de idéias, valores e produtos culturais de toda a procedência. Recrudesce a tensão entre forças homogeneizadoras e heterogeneizadoras nos mercados culturais globalizados resultado do crescimento de diferentes ramos da indústria cultural e sua concentração em mega-conglomerados de cultura de massa, com apetite voraz por novos mercados e uma certa tendência a determinar a oferta cultural pelo mínimo denominador comum. A discussão sobre a produção cultural ganha nova importância política, econômica e estratégica. O comércio internacional R. Inter. Interdisc. INTERthesis, Florianópolis, v.6, n.1, p. 254-278, jan./jul. 2009 
de produtos (bens e serviços) culturais, que compreende a indústria cinematográfica e do audiovisual, a televisiva, a radiodifusão, a indústria fonográfica, a editorial e de software, entre outras formas de expressão cultural, é a área mais dinâmica da economia mundial; por isso mesmo, os mercados para o escoamento desses bens são objeto de implacável disputa.

É do economista John Kenneth Galbraith a afirmação de que as indústrias criativas são o componente-chave da vida econômica do século XXI. De fato, são extraordinários a dimensão e o dinamismo dos conglomerados industriais que se foram formando desde fins da primeira década do século XX. O comércio de bens e serviços culturais ganha cada vez mais destaque na pauta de exportação de alguns países, principalmente dos EUA. O comércio de bens e serviços corresponde a cerca de $25 \%$ dos fluxos globais no mercado internacional e apresenta taxas de crescimento, a cada ano, consistentemente maiores. Como os EUA, o Japão, Inglaterra, França e Canadá elaboram ambiciosas estratégias para aumentar a competitividade de seus produtos e estimular a chamada pauta de "exportações de conteúdo". As mais bem sucedidas indústrias culturais dos países desenvolvidos se agrupam em alguns grandes conglomerados, que dominam grandes fatias do mercado global. Os números dos diferentes ramos da indústria cultural crescem em nível exponencial e tendem a se expandir ainda mais ao longo do século XXI. Se existem limites físicos para a importação de matérias primas, a era da distribuição de massa, e da internet eliminou quaisquer limites numéricos para a importação de conteúdo cultural.

Os produtos de natureza cultural, que os americanos qualificam de "entretenimento" para grande irritação dos franceses, vêm penetrando em todos os mercados, da Patagônia ao Tibete, levando na esteira de seu sucesso um espectro de valores, conceitos, sentidos, desejos e padrões de consumo novos, que ao se impor, transformam as culturas locais. Se o crescimento sem precedentes da tecnologia de informação tem o poder de promover a diversidade de conteúdos, é verdade também que a pletora de oferta de produção estrangeira pode inibir o desenvolvimento da cultura local, ou esgarçar seu tecido a ponto de extingui-la. Assim, muitos países vêem nesse fluxo internacional acelerado de produtos culturais uma "invasão", ou uma ameaça a sua identidade cultural ou nacional. Fala-se de "imperialismo cultural", sobretudo porque se amplia a penetração da indústria de 
entretenimento norte-americana, que já é hoje a segunda maior rubrica da pauta de exportação dos EUA. Franceses e canadenses vocalizaram esta percepção com significativa ênfase, mas a adesão de tantos países à idéia torna patente que este sentimento é razoavelmente comum.

A necessidade de redigir um conjunto de normas para defender as identidades culturais e os direitos dos povos de promover suas próprias culturas surge dessa sensação de que, por mais resistentes que sejam culturas como a chinesa, a japonesa, a indiana e mesmo a brasileira, a defesa natural contra a avalanche de produtos culturais norte-americanos exigiria atos de resistência explícita, como um programa de políticas públicas culturais, para promover o crescimento da indústria cultural doméstica através de incentivos, subsídios, subvenções e reservas de mercado.

No entanto, a crescente interdependência das economias nacionais e a emergência de regimes de regras para as relações econômicas internacionais dos acordos de comércio bilaterais e multilaterais criaram uma situação na qual compromissos e disciplinas internacionais limitam a execução de políticas públicas nacionais. Nas atividades de natureza cultural, o arcabouço de políticas públicas para incentivar o setor normalmente está baseado em três vertentes: 1) o apoio financeiro (subvenções, subsídios, empréstimos, garantias e renúncia fiscal), 2) as exigências de conteúdo local (basicamente as quotas de conteúdo local) e, 3) as restrições ao capital estrangeiro. Essas medidas, em suas três vertentes, contrariam frontalmente as regras dos acordos de livre- comércio, que procuram remover barreiras ao comércio internacional e para as quais a discriminação entre nacional e estrangeiro é um anátema.

A tendência à interdependência internacional está se acentuando ano a ano, e a desregulamentação, a privatização e a abertura de mercados se aceleraram, passando a constituir os pilares do processo de integração econômica global. No que tange às políticas culturais domésticas, as regras de comércio são percebidas como particularmente impositivas, e mesmo constrangedoras. As regras multilaterais de comércio da OMC, longe de serem inócuas, têm sérias conseqüências para as políticas culturais dos países signatários dos acordos de livre-comércio. Exemplo disso é o contencioso que opôs os EUA ao Canadá na questão dos periódicos e revistas, logo após a assinatura do acordo de livre-comércio entre os dois países, o 
NAFTA. A questão instaurou importante precedente que em muito contribuiu para a percepção de que era necessária uma Convenção que tratasse a cultura em termos culturais. A disputa entre os EUA e o Canadá centrou-se nas medidas introduzidas pelo último para resguardar a indústria de periódicos e revistas, para a qual não havia feito reservas explícitas no Acordo. O Canadá defendeu-se alegando que essa indústria era um meio para refletir e divulgar as concepções canadenses sobre o mundo, e para promover a cultura canadense. Os EUA fizeram objeções às medidas com base no argumento de que elas eram puramente protecionistas e contrárias às regras do acordo. Deu-se início aos procedimentos de solução de controvérsias da OMC, que levaram a uma decisão desfavorável ao Canadá. Assim, não parece descabido o temor que a maioria dos países nutre de colocar na mesa de negociação restrições a sua capacidade de fomentar e estimular a própria cultura interna.

Por outro lado, e talvez mais importante, as políticas de patrocínio e subsídio à cultura não se limitam a ajudar a manter formas de expressão cultural e a fomentar setores com potencial econômico, elas têm, sobretudo, quando bem executadas, poder transformador. Essas políticas estão imbricadas no grande desafio do mundo contemporâneo: o desenvolvimento econômico.

De fato, cultura e desenvolvimento são conceitos que se interpenetram. A relação entre os dois, sobre a qual nos debruçaremos mais adiante, atravessou três momentos nas últimas décadas : nos anos cinqüenta, grosso modo, questionava-se se características culturais não constituiriam obstáculos ao desenvolvimento; nos anos setenta, a cultura já era concebida como componente estratégico do desenvolvimento; hoje em dia a cultura é não só elemento essencial, mas um objetivo em si do desenvolvimento. Cultura e educação exercem o mesmo papel de emancipação do indivíduo e das coletividades. Privar comunidades culturais dos meios e formas para manter e fazer evoluir seus discursos simbólicos próprios significa favorecer a penetração indiscriminada de produtos culturais criados em outras realidades. A troca de discurso simbólico próprio por outro, alienígena, provoca não só a gradativa aniquilação das peculiaridades da produção local como impede que esta comunidade um dia alcance o desenvolvimento, na plena acepção da palavra. Ambos são efeitos altamente indesejáveis. Dessa forma, a legitimidade das políticas públicas destinadas a promover a cultura reside no fato de que a 
cultura expressa a identidade íntima de povos e indivíduos, constitui marco de afirmação das liberdades civis, mas é, sobretudo, fator de desenvolvimento.

A Convenção é a ponta de um iceberg e um ponto de inflexão, talvez não o último, de uma longa história, que já recebeu o epíteto "a guerra não-declarada". Essa guerra remonta à origens do cinema o mais lucrativo, arriscado e significativo dos produtos culturais, ao longo de todo o século $\mathrm{XX}$. Essa guerra remonta às lutas por registro das patentes e teve batalhas decisivas nos anos 1920-30, com o estabelecimento de quotas de tela na Europa.

As quotas de tela que reservam espaço para a produção doméstica foram impostas pelos países europeus com o objetivo de fomentar suas nascentes indústrias de cinema e coibir a avassaladora invasão de filmes norte-americanos. $A$ disputa, na qual se fundem interesses de mercado, flutuações de índices de produção e preconceitos nacionais começa muito antes, no início da história da invenção das máquinas que tornavam possíveis as imagens em movimento. A França sempre reivindicou a si a invenção do cinema, referindo-se para isso às demonstrações públicas dos irmãos Lumière, em 1895. Os Estados Unidos creditam ao inventor Thomas Alva Edison a primazia. Edison visitou a Grande Exposição de Paris, em 1889, e ficou impressionado com uma nova máquina desenhada pelo francês Etienne Marey, chamado "cronofotógrafo". Dois anos depois, em 1891, Edison lançou nos EUA uma invenção semelhante, chamada "kinetoscope", que consistia em uma caixa de madeira com buraco para ver imagens em movimento, movida a eletricidade. O histórico desses tempos em que o cinema era considerado uma invenção sem muito futuro, entretenimento barato para as massas urbanas que jamais poderiam sonhar em distrair-se com o teatro, a ópera ou os shows de vaudeville, é cheio de peripécias e testemunha a rivalidade entre os EUA e a França, que ainda hoje perdura. Desde os primórdios, franceses e americanos, ao se darem conta do potencial do novo meio de difusão cultural, se empenhavam com unhas e dentes para assegurar para si o novo filão.

Em um primeiro momento, a França parecia ter largado à frente. Graças a visão de Charles Pathé, na primeira década do século $X X$, a França era líder na produção de filmes. Em 1908 os filmes franceses dominavam 70\% do mercado 
norte-americano. À semelhança do que mais tarde fariam os estúdios americanos, a Pathé Frères seguia o modelo de "integração vertical”, que constituiria décadas depois a força dos estúdios norte-americanos, na qual a empresa era não só a fabricante dos equipamentos, como também a produtora dos filmes, a distribuidora nos mercados e a dona das salas de cinema. As exportações eram essenciais, pois, como aprenderam os americanos mais tarde com relação ao cinema e a TV, exportar significava a diferença entre o lucro e a bancarrota. Do outro lado do Atlântico as companhias americanas resistiam por todos os meios à penetração dos filmes estrangeiros, em uma curiosa inversão de papéis com relação ao que se vê hoje. No início da história do cinema, quem detinha as máquinas, produzia também o conteúdo para exibir a invenção. Em 1896, por exemplo, as demonstrações de novos projetores, feita pelos irmãos Lumière nos EUA, foram saudadas com boicotes, confisco de equipamento na alfândega, "inexplicáveis" cancelamentos e até o espancamento dos exibidores. O primeiro escritório em solo americano da Pathé, aberto em 1904, enfrentou processo por violação de patente movido pela Edison Manufacturing Company. Em 1907, Edison e seus rivais domésticos juntaram forças formando a Motion Picture Patents Co., cujo principal propósito era "limitar ou extinguir as marcas estrangeiras com permissão para circular dentro nos Estados Unidos". As exportações de filmes franceses para os EUA continuou incomodando os produtores americanos até a Primeira Guerra Mundial, quando a devastação econômica tornou a produção de filmes em solo europeu insignificante.Com o avanço da guerra, os mercados de cinema viraram terra de ninguém. O flagelo na Europa representou a grande oportunidade do cinema americano. Naquele momento, Hollywood, local de terras semi- desérticas e baratas, onde se instalaram os maiores estúdios, desenvolvia sua forma de fazer filmes. As produções americanas exibiam imagens novas, ausentes da produção francesa pré-1914. Estes novos filmes já não se limitavam a "sketchs" humorísticos ou a filmagem de trens em movimento. Hollywood instaurou um novo estilo de contar estórias, com o uso de técnicas e truques para manter a "continuidade narrativa", o que tornou imbatível a atração que exercia sobre as audiências. Quando a Primeira Guerra acabou, Hollywood havia se tornado uma potência exportadora.

Do lado dos países consumidores no entanto, paralelamente aos temores pelo impacto econômico- comercial, sempre houve uma preocupação grande com a R. Inter. Interdisc. INTERthesis, Florianópolis, v.6, n.1, p. 254-278, jan./jul. 2009 
influência do conteúdo dos filmes americanos. No início da era do cinema, na Europa, os filmes produzidos nos EUA eram vistos como mera propaganda americana às expensas da verdade - como por exemplo as filmagens da parada militar sob o Arco do Triunfo, por ocasião da vitória de 1919, produzidas pela MGM, que mostravam, com garbo e parcialidade, "apenas" as tropas americanas passando. Era fácil constatar que havia uma coincidência de interesses industriais, políticos e culturais no projeto explícito dos EUA, que para conquistar mercados, precisavam conquistar "as mentes e corações" dos consumidores, com isso ganhando mercados não só para suas produções como também para outros produtos. De fato, como veremos adiante, a influência dos grandes estúdios junto ao Departamento de Estado norte-americano sempre foi notável e é referida em muitos textos sobre o tema. Essa congruência de interesses, consciente para empresários e Departamento de Estado, é determinante do sucesso alcançado pela indústria de cinema norte-americana, mas sempre provocou reações de desagrado.

A Alemanha, que já havia determinado o embargo de bens não essenciais em 1916, incluindo filmes, decidiu estender seu protecionismo, e, em 1921 impôs as primeiras quotas para a entrada de filmes produzidos no estrangeiro. As razões que alegou a Alemanha para introduzir o regime de quotas mesclavam valores culturais, como a defesa da língua e o nacionalismo patriótico, com preocupações industriais. Esses argumentos informaram as posições de muitos outros governos europeus, que seguiriam o mesmo caminho e instaurariam o regime de quotas. As lutas, revezes e resultados na aplicação das quotas tiveram impacto na formação e crescimento das indústrias de cinema na Europa no período que antecede o fim da Segunda Grande Guerra.Com o fim da guerra e a vitória dos aliados, os EUA voltam a dominar os mercados em função de situações como a criada pelos Acordos BlumByrnes, firmados em 1946 com a França, que atrelaram a concessão de capitais para a reconstrução do pós-guerra à abertura dos mercados para os filmes americanos. Os esforços de Hollywood para assegurar acesso ao mercado francês foi estendido aos demais países da Europa. Dois meses após o fim da guerra, os principais estúdios americanos ( Columbia, 20th Century- Fox , Warner Bros., e MGM) visitaram a Europa a convite do Comandante Supremo das tropas aliadas, General Dwight Eisenhower. Mesmo nos países que não haviam instituído quotas, havia resistência à repatriação de fundos, em função da dificuldades econômicas 
decorrentes do conflito. O período de pós-guerra foi pontuado por uma pulverizada ofensiva americana de procurar brechas de penetração e bloquear as tentativas dos países europeus de limitar os mercados e taxar seus lucros. Os anos cinqüenta e sessenta conheceriam o triunfo o indústria de cinema americano e criariam as condições para a o surgimento da resistência a essa hegemonia na formulação do conceito de "exceção cultural". A exceção cultural surge porque a decidida agressividade das iniciativas norte-americanas de promoção de uma de suas mais lucrativas indústrias, acabou por dar legitimidade à situação em que as políticas culturais internas não são concebidas apenas para incentivar os setores culturais, mas sim, em grande parte como um sistema de defesa de mercados.

Os anos se passaram. As políticas culturais se sofisticaram na Europa, no quadro da social-democracia do pós-guerra. A animosidade de posições entre a França, defensora da "exceção cultural", e os partidários da liberação progressiva dos mercados internacionais do audiovisual, no quadro das negociações comerciais, liderados pelos EUA, foi sendo nutrida até chegar a seu ápice no final da Rodada Uruguai, quando os países europeus resguardaram-se de fazer ofertas de mercado no setor de serviços referentes a listas de produtos culturais, esgrimindo o argumento de que estes mercados e produtos tinham um caráter "especial", e por isso não poderiam ser tratados como quaisquer outros produtos comerciais.

O núcleo do debate está na questão do tratamento a ser conferido aos produtos (bens e serviços) de natureza cultural nos foros multilaterais. A definição dos produtos tem enormes conseqüências econômicas e comercias. Trata-se da questão crucial do acesso a mercados, por um lado, e da ameaça, real ou fictícia não importa, de um desfibramento da identidade nacional pela composição do imaginário através da visão estrangeira.

Duas visões se opõem na arena na qual vicejaram as contradições e antagonismos que fizeram surgir a Convenção: 1) a visão, defendida pelos EUA, de que bens e serviços culturais constituem "produtos de entretenimento", e como qualquer produto, devem ser submetidos às regras da Organização Mundial do Comércio (OMC), as quais preconizam a progressiva liberalização dos mercados nacionais à entrada de produção estrangeira sem qualquer discriminação de nacionalidade; e 2) a visão, defendida pela França, e pela Europa em geral, de que bens e serviços culturais não podem ser considerados meros produtos comerciais 
porque são portadores de valores, idéias e sentidos, e formam a expressão da identidade de povos e comunidades. A frase que sintetizou essa posição, e se tornou um slogan, foi elaborada pelo ex-Ministro da Cultura francês, Jacques Delors, mas foi proferida oficialmente pelo ex-presidente francês François Mitterrand, ao final da Rodada Uruguai da OMC: “La culture n'est pas une marchandise comme les autres". Significava que filmes e canções não podem receber um mesmo tratamento, ou se submeterem às mesmas regras multilaterais de comércio, que produtos como aço ou bananas. As expressões culturais são portadoras de sensibilidades, impressões subjetivas, exortações e mensagens; elas informam, formam projeções coletivas, moldam atitudes sociais, educam, ou impressionam de forma profunda a psique humana. Em suma, calam fundo no indivíduo e forjam as identidades coletivas de que se compõe a humanidade, as quais, não obstante a necessidade da inter-polinização, necessitam primordialmente do direito de ter representações próprias, que expressem sua identidade única e suas peculiaridades, sob pena de perecerem.

Essa posição, que vê o produto cultural como portador de um papel "especial", teve como uma de suas conseqüências práticas a concepção da idéia da "Exceção Cultural". A tese, defendida com veemência pelos franceses, com apoio da maioria dos países da Europa ocidental, foi concebida como resposta européia à proposta norte-americana de discutir a liberalização comercial dos mercados culturais no âmbito do Acordo Geral sobre Comércio de Serviços, o GATS (General Agreement on Trade and Services). A tese da "Exceção" à francesa, como ficou conhecida, paralisou as negociações da Rodada Uruguai, onde o GATS foi negociado, e representou um marco do acirramento dos ânimos em torno do assunto.

O impasse no final da Rodada Uruguai foi considerado pelos EUA“ um fracasso". Para os europeus foi uma bela "vitória da cultura sobre o comércio". Nem uma coisa nem outra: o antagonismo sobre o tema continuou no topo da agenda internacional em todos os foros, no contexto dos acordos bilaterais ou regionais que estão sendo assinados, na fracassada negociação sobre o Acordo Multilateral de Investimento (AMI), sempre que as indústrias culturais são mencionadas.

A tese da "Exceção Cultural" está hoje superada, substituída pelo tema amplo e consensual da "Diversidade Cultural". A "Exceção" assustava porque foi envolta R. Inter. Interdisc. INTERthesis, Florianópolis, v.6, n.1, p. 254-278, jan./jul. 2009 
em arroubos retóricos radicais, e porque os países em desenvolvimento perceberam o risco de que a tese se tornasse apenas uma política protecionista, pronta para ser estendida a outros setores, como a agricultura, por conta de interpretações tendenciosamente amplas do que seria a cultura, em prejuízo de países que, como o Brasil, estão interessados na abertura de mercados para produtos agrícolas. A exceção está hoje transformada pelos próprios termos da Convenção, que não só circunscrevem a definição de cultura dentro de limites consensualmente acordados, como também dão ênfase à interação, ao intercâmbio e à necessidade de trocas interculturais. Nunca é demais reiterar que uma aplicação estrita da "Exceção Cultural" poderia, ironicamente, ameaçar a diversidade que pretendia defender, já que a proteção da identidade cultural levada a extremos seria a antítese da garantia de acesso a mercados para exportação de cultura, seria o veneno para o intercâmbio e a síntese necessários à vitalidade e transformação permanente que são próprios da cultura.

No entanto, há que reconhecer que os objetivos de liberalização, constantes da letra dos acordos de livre-comércio, não implicam que as chamadas "Non-trade public policies", como a promoção cultural, ou a proteção ao meio-ambiente, devam necessariamente ser atingidas negativamente. Não obstante não haver nada na ordem econômico-comercial internacional que sugira um regime específico para os bens culturais ou serviços, pode-se argumentar que os acordos no âmbito do sistema da OMC, particularmente o Acordo sobre o Comércio de Serviços (GATS), seguindo a tradição de seu antecessor, o GATT, que legitimou o recurso às quotas de tela poderiam reconhecer a possibilidade de soluções diferenciadas para setores culturais sensíveis. O GATT, sigla em inglês do acordo sobre o comércio de bens, o General Agreement on Tariffs and Trade, data de 1947, e já trazia prevista, em seu artigo IV, uma exceção para o audiovisual, lograda por pressão dos europeus que desejavam conservar a vigência das quotas de tela, entendidas como importante instrumento do arcabouço jurídico de proteção à cultura.

Embora seja verdade que países economicamente mais poderosos, como os EUA, em muito se beneficiam das regras dos acordos comerciais da Organização, parte das regras do GATS podem ser interpretadas de forma a beneficiar os países em desenvolvimento e não-desenvolvidos. A forma como o Acordo funciona, através R. Inter. Interdisc. INTERthesis, Florianópolis, v.6, n.1, p. 254-278, jan./jul. 2009 
de oferta e pedido de acesso a mercados, oferece flexibilidade e latitude na decisão sobre a abertura de setores de serviços. A Organização tem demonstrado que seus objetivos são regular de forma ordeira e previsível as atividades econômica e comercial, a fim de garantir os objetivos da liberalização, mas que tem certa maleabilidade para lidar com assuntos sensíveis. É preciso que se diga, contudo, que essa tolerância é muito fragmentária e deverá ser aperfeiçoada caso a caso, através da análise e da discussão do impacto do sistema instituído pela Organização sobre os interesses não-comerciais prioritários dos países que a compõem.

Para muitos países, a despeito de seu estágio de desenvolvimento, não interessa aderir às teses francesas de defesa exacerbada e protecionista dos mercados culturais, pois a abertura negociada e justa de parcelas dos mercados culturais pode significar o acesso amplo da produção cultural a mais amplas audiências, em cumprimento aos desígnios da bandeira da diversidade cultural. Para o Brasil, que já exporta novelas para mais de cem países, tem na música um de seus produtos culturais com maior qualidade e sucesso internacional, e que tem ambições de tornar-se exportador de conteúdos não interessa assumir posição na qual a recusa a negociar mercados possa constituir um impedimento a expandir suas exportações. A proteção da cultura local através do fechamento de mercados tem sua contrapartida - ou seja a proteção que os parceiros comerciais do Brasil fariam em seus próprios mercados contra influências externas excessivas - o que poderia ter sérios efeitos limitadores para as exportações de produtos e serviços culturais brasileiros .

Por essa razão o Brasil, que trabalhava intensamente nas várias Organizações governamentais e não-governamentais que discutiam as questões da Diversidade Cultural e a preparação dos termos da Convenção, apresentou em 2001, no seio da Organização Mundial do Comércio uma proposta de discussão, a " Comunicação do Brasil sobre Audiovisual à OMC". Qual é a razão da proposta brasileira? O Brasil foi, naquele momento, mal interpretado. O "Le Monde" chegou a publicar artigo dizendo que o Brasil havia "traído" a causa da "Diversidade Cultural". As redes internacionais de organizações voltadas para a campanha por um instrumento sobre a diversidade cultural na UNESCO, das quais o Brasil fazia parte, protestaram contra a comunicação. Mas a comunicação do Brasil à OMC sobre 
audiovisual reconhecia, em seu próprio texto, a validade das premissas que informam o tema da diversidade cultural.

O Brasil submeteu comunicação circular entre os membros do Conselho de Comércio de Serviços, em 9 de julho de 2001. A proposta tinha como objetivo oferecer uma solução nova que evitasse a dicotomia que se estabeleceu entre os defensores da "Exceção cultural", liderados pela França, e os partidários da liberação progressiva do audiovisual, liderados pelos EUA. As intenções do documento, constantes do primeiro parágrafo, são: a) promover a progressiva liberalização do audiovisual e ao mesmo tempo assegurar a autonomia dos governos para preservar e promover a identidade e a diversidade cultural; b) contribuir para a discussão sobre a melhor forma de atingir esses objetivos, incluindo a regulamentação do uso de esquemas de subsídios e mecanismos de defesa comercial; e c) contribuir para aumentar a participação dos países em desenvolvimento no comércio de serviços.

O texto ressalta a sensibilidade política envolvida no tema, que se reflete na ampla regulamentação e nos poucos compromissos de liberalização desses setores assumidos pelos países nos acordos multilaterais de comércio, como o GATS. Ao referir-se à contenda entre as duas posições conflitantes na Rodada Uruguai, critica o argumento da "exceção cultural" porque não leva em conta que os produtos e serviços culturais são efetivamente parte de uma indústria com clara importância econômica e comercial, que envolve substantivos interesses para alguns países em desenvolvimento. Mas ressalva ser inegável que os serviços audiovisuais têm papel importante na transmissão e difusão de idéias e valores culturais. A comunicação recorda que a estrutura do GATS que comporta compromissos de Tratamento Nacional "negociáveis" e a manutenção da prerrogativa regulatória dos Membros, concede ampla flexibilidade para a oferta e consolidação de compromissos, permitindo em boa medida a defesa dos interesses de política cultural interna dos Estados-parte. Pondera, contudo, que em face da aludida sensibilidade do setor, devam ser considerados instrumentos adicionais, como os mecanismos de subsídios, particularmente na produção e distribuição de filmes. O documento brasileiro também menciona a estrutura oligopolística do setor e a questão da colocação dos produtos audiovisuais por meio de dumping em mercados estrangeiros, configurando concorrência desleal, o que forçaria a saída da produção 
doméstica das salas de cinemas e outros meios de difusão como a TV aberta, a cabo, e outros meios eletrônicos. A filosofia da proposta brasileira era a seguinte: dada a situação de fato dos mercados internacionais do audiovisual, claramente dominados de forma desequilibrada por um só fornecedor (os EUA), a melhor maneira de lidar com a situação seria recorrer aos próprios mecanismos comerciais para corrigir as distorções provocadas por essa dominação.

O que o Brasil quis com a proposta foi justamente tornar mais claras as noções de salvaguardas, antidumping e subsídios a fim de tornar operacionais dispositivos da chamada "agenda inacabada" do GATS, que não vêm sendo usados atualmente, e que poderiam favorecer os interesses de países em desenvolvimento. O Brasil procurou sobretudo ver formas de fazer as regras do sistema trabalharem a seu favor. A discussão permanece em aberto, e diga-se de passagem, o Brasil não apresentou até o momento nenhuma oferta nos Serviços de Audiovisual e nem contraiu qualquer compromisso nem em relação aos setores culturais, nem em relação a investimentos ou comércio eletrônico.

A posição defendida pelo Brasil corresponde à inquietação quanto ao futuro das exportações brasileiras. A TV Globo exporta novelas para toda a Europa, alguns países de Ásia e da América Latina, e tem difusão a cabo cobrindo todo o continente europeu, os EUA e o Japão. A decisão anunciada por Pascal Lamy, o então comissário europeu para o comércio, de excluir o audiovisual, ao lado da educação e saúde, das negociações na OMC, em 2003, poderia significar a decisão de cassar transmissões ou restringir a compra de novelas estrangeiras por seus países membros. No momento não há entraves para as retransmissões brasileiras. Mas é bom que se frise, nesse terreno não há direitos assegurados. Os países que pediram na OMC para a União Européia negociar melhor o acesso da produção audiovisual foram o Brasil, os Estados Unidos, Japão, China e India, justamente porque a exclusão desse setor por parte dos europeus pode reduzir a possibilidade de crescimento das exportações desses países.

A Comunicação sobre Audiovisual apresentada pelo Brasil em 2001 foi bem recebida na $\mathrm{OMC}$, que a considerou construtiva, especialmente porque passa ao largo das posições extremadas que caracterizaram os embates na Rodada Uruguai entre a tese da "Exceção Cultural", defendida pela França, e o voluntarismo algo 
ganancioso norte-americano de considerar o audiovisual como um setor qualquer, ao qual as regras do GATS seriam aplicáveis in totum.

Já se disse da chamada "guerra não declarada" pelo controle da indústria mundial de cinema e o conseqüente temário da "Diversidade Cultural", que tudo isso não passaria de uma disputa entre países "ricos", em defesa de suas já ultraprotegidas indústrias culturais. Outros diziam que o tema era de pouco interesse para o Brasil porque seria uma birra de franceses, agastados com a invasão da "banalização à americana"; alguns apontaram também, com alguma razão, que aliarse incondicionalmente às bandeiras da União Européia, por mais corretas que parecessem no que diz respeito aos embates entre cultura e comércio, seria concordar com teses que preconizavam restrições de acesso a mercados, as quais poderiam afetar as exportações brasileiras de conteúdo para aquele continente no futuro. Também já se disse que o Brasil, mesmo sendo um país ainda em desenvolvimento, é, sem dúvida, uma "potência cultural". Então, quais seriam os interesses do Brasil na qualidade de produtor de conteúdo, com grande potencial de desenvolvimento? Que orientação de fundo deveria seguir o Brasil em futuras negociações internacionais que toquem no tema, tanto na esfera cultural quanto comercial?

As discussões na Rodada Uruguai fizeram emergir com clareza dois campos opostos: o dos excepcionalistas, partidários da "Exceção Cultural", e o dos livrecambistas, partidários do livre-comércio (também chamados de hyper-liberals pelos europeus). Os excepcionalistas tiveram que submeter-se à transição semântica e política das formulações da tese da "Exceção Cultural" para a defesa da "Diversidade Cultural", a fim de arregimentar mais países para suas posições. Muitas das premissas da "Exceção" ainda se mantêm e as políticas culturais com base em seus conceitos continuam sendo implementadas. Estabelecer mercado reservado à produção nacional e conceder subsídios a sua produção, provenientes de fundos formados pela cobrança de taxas sobre a exibição de produção estrangeira, são alguns dos mecanismos usados para preservar a circulação de bens e serviços locais dentro dos mercados nacionais. Como essas medidas contrariam as regras multilaterais de comércio, que preconizam a abertura e a não-discriminação entre nacional e estrangeiro (cláusula da Nação Mais Favorecida), as duas diretrizes dos que aderem à posição de defesa da diversidade cultural são hoje: 1) a defesa do 
direito de manter ou criar políticas internas infensas a essas regras; e 2) não fazer ofertas de compromissos, que envolvam os setores de produção cultural no quadro do GATS. No entanto, pressões para que sejam feitas ofertas de liberalização prosseguirão no quadro da OMC porque fazem parte do mandato daquela Organização e pressões continuarão ser feitas pelos EUA no quadro dos acordos bilaterais de livre-comércio. Desta forma, mesmo que a "Diversidade Cultural" tenha atenuado a "Exceção Cultural", a questão que opõe excepcionalistas e livrecambistas no que toca às regras multilaterais de comércio e as políticas públicas, reteve seu frescor e será reeditada cada vez que forem discutidas nos foros internacionais as indústrias culturais. Para examinar como ao Brasil não interessa alinhar-se a nenhum dos dois lados, embora possa concordar com alguns dos pressupostos de um e outro, examinemos as premissas de cada um.

Economicamente, os excepcionalistas vêem o mercado global como um falso mercado, dominado por um pequeno número de mega-corporações formadas a partir de matrizes americanas. Esse mercado, por suas características de rede de monopólios concede espaço muito escasso para a diversidade de conteúdo. Os excepcionalistas rebatem o título de protecionistas com que foram brindados pelos americanos, denunciando o protecionismo maior dos EUA, que importa apenas algo em torno de $1 \%$ de produção cultural estrangeira. Aduzem que o GATT, e depois a $\mathrm{OMC}$, se apóiam nas teorias do livre comércio, que são estruturalmente inadequadas para lidar com a cultura. Para ilustrar seu ponto de vista, explicam que Adam Smith e David Ricardo lograram explicar como as trocas internacionais, a abertura dos mercados e a divisão internacional do trabalho são fonte da produtividade, de crescimento e de prosperidade gerais, mas que esses princípios são inapropriados para dar conta das trocas de produtos culturais. Se é verdade que cada país teria interesse em se concentrar na produção de bens nos quais possui vantagens comparativas, e se a divisão internacional do trabalho é induzida pela especialização das economias nos domínios nos quais são mais competitivas, a questão é saber - uma vez que alguns países querem tratar de setores culturais na OMC - como ficaria a cultura, se o princípio da especialização e da divisão internacional do trabalho se aplicasse a ela ? Tendo os EUA indiscutíveis vantagens comparativas na produção de blockbusters, tornar-se-ia ele idealmente o fornecedor exclusivo do cinema mundial? Dessa forma, concluem os excepcionalistas, sem a 
intervenção dos Estados em seus espaços nacionais, através das políticas culturais internas, o cenário de uma Hollywood sem concorrentes seria possível, e poderia ser estendido a todos os outros setores culturais que se revelassem rentáveis, ressecando a diversidade e uniformizando os conteúdos em favor de um único fornecedor mundial.

Assim, os Estados teriam a responsabilidade de compensar os desequilíbrios do mercado e os Governos estariam tacitamente autorizados a proteger as indústrias de conteúdo cultural e de mídia, porque estas, a par de serem de alto risco financeiro em função de suas dimensões, têm a capacidade primordial de refletir a identidade. Assim, seria apanágio do Estado, como vetor das coletividades culturais, tomar medidas "afirmativas" tais como as quotas, a fim de reduzir o impacto da invasão de produtos mais baratos de indústrias estrangeiras em seus mercados culturais. Ppara os excepcionalistas os mercados devem ser em ampla medida controlados e a entrada de produtos estrangeiros restringida. Culturalmente, os excepcionalistas vêem a cultura como essência humana não comercializável, e o cinema e o audiovisual não como entretenimento, mas como arte e patrimônio.

Os livre-cambistas ao contrário, consideram o cinema uma indústria que produz entretenimento e rejeitam a idéia de que deva ser protegida. Os EUA argumentam que não praticam qualquer tipo de política federal para regular as comunicações, as informações e a cultura. Estas atividades devem ser livres e se moldar e conformar às inclinações do mercado. Sem qualquer ambigüidade na formulação, ou inquietude quanto às conseqüências funestas apontadas pelos excepcionalistas, os livre-cambistas pressionam pela extinção de todas as restrições alfandegárias e subsídios estatais aplicadas aos produtos culturais, principalmente o cinema, sua segunda mais importante indústria. Para os livre-cambistas, o sistema multilateral de comércio, a prosperidade e a segurança constituem um trinômio, fundamental para o progresso e o combate à pobreza. Não obstante a oscilação entre o conservadorismo e as políticas dos democratas, depois da segunda Guerra Mundial, o lugar comum da política externa norte-americana tem sido a promoção do livre comércio e a livre circulação de capitais na cena internacional. Os interesses americanos, sejam eles comerciais ou geopolíticos, estão imbricados nesta agenda, baseada em um sistema de valores que incumbiria aos EUA promover, difundir e defender em nome do bem comum e da luta contra a pobreza. Sem entrar no mérito 
sobre o fato de que muitas vezes os próprios Estados Unidos utilizam protecionismo e práticas desleais para favorecer seus interesses, a retórica da política internacional dos EUA defende regras que, em sua ótica, deverão ser entendidas como uma cooperação institucionalizada e uma adesão universal a princípios fundamentais.

A pá de cal é jogada com o argumento de que o determinismo tecnológico e a evolução digital terminarão por enterrar as políticas nacionais, favorecendo a disseminação da produção daqueles que forem mais aptos a produzir nos novos formatos.

As contendas entre as duas posições, que alimentaram debates diplomáticos, incendiaram as organizações de profissionais da cultura em muitos países, mobilizaram governos e organismos internacionais, acabaram por enrijecer o arsenal de argumentos de ambos os lados. Mas é importante que se entenda que os objetivos dos europeus podem ser vistos como simétricos dos objetivos americanos: competitividade internacional, equilíbrio comercial interno, preservação do emprego, desenvolvimento das indústrias culturais, e descentralização da produção artística. A diferença é que o ponto de partida dos europeus é socio-cultural e o dos americanos é econômico. O Brasil pode concordar com várias das premissas dos excepcionalistas, e o fez no contexto das negociações da UNESCO, mas interessaria ao país que restrições fossem impostas a entrada de produtos, e medidas de discriminação entre nacional e estrangeiro tivessem vigência, a ponto de impedir a comercialização da produção de cinema, TV e música brasileira em mercados estrangeiros?

A crise e o impasse entre as duas posições, em 1993, ao final da Rodada Uruguai, revelou com clareza que nenhuma das duas posições servia ao Brasil. A rivalidade e o antagonismo das discussões entre as duas posições revelaram que o debate naquele momento não era uma questão "global", mas dizia respeito a idiossincrasias próprias das disputas de mercado, no caso o europeu. A "exceção cultural", no que refletia as posições francesas versus o liberalismo, na versão primária e crua dos EUA, não se enquadrava no universo da política externa de muitos países, entre eles o Brasil. Paralelamente emerge uma gama de países, com interesses semelhantes, para os quais a equação era mais complexa: os benefícios da globalização, no que diz respeito à abertura de mercados, seriam muito bem- 
vindos, desde que, e este ponto é fundamental, não se realizassem em detrimento de sua produção cultural, sua identidade e língua.

Paralelamente evoluíam as discussões na esfera cultural. A arregimentação de aliados para as posições da União Européia, facilitada pela mudança, política, diplomática e semântica, de "exceção cultural" para "Diversidade Cultural" foi sendo fortalecida por iniciativas na esfera multilateral, como a Rede Internacional sobre Políticas Culturais (RIPC), cujo objetivo era " tornar a Diversidade Cultural parte integrante da reflexão mundial sobre o desenvolvimento". A Rede Internacional para a Diversidade Cultural, que tem um braço no Brasil através do Instituto Diversidade Cultural, presidido por Leonardo Brant, e outras tantas organizações não governamentais e intergovernamentais, alertadas pelos embates na esfera econômico-comercial convergiam para a idéia de que era necessário um instrumento normativo que garantisse a possibilidade dos Estados implementarem políticas culturais infensas às regras multilaterais de comércio. As primeiras reuniões, de que participou o Brasil, se realizaram e tiveram como um de seus mais notáveis resultados indiretos a "Declaração Universal sobre a Diversidade Cultural", adotada pela UNESCO em outubro de 2001. De fato, o guarda-chuva teórico da "Diversidade Cultural" abrigava bem tanto os Europeus quanto os países de médio porte, que alimentam o desejo de construir uma plataforma de exportações de conteúdos culturais. Nesse sentido o Brasil podia facilmente se alinhar politicamente a essa posição, coisa que fez com decisão, sobriedade e protagonismo durante as negociações da UNESCO, pois se trata de afirmar a autonomia e a diferença, e assegurar que em âmbito nacional nada possa impedir a subvenção e outras medidas de estímulo às indústrias criativas que refletem as identidades nacionais. Esses mesmos princípios haviam ficado subscritos no texto da lei que criou a agência de cinema brasileiro, a ANCINE, e se coadunam perfeitamente com o programa do Ministério da Cultura, cuja prioridade é a defesa da diversidade cultural.

Assim, o Brasil tem assumido, em todos os foros onde o tema da interface comércio e cultura é discutido, a posição de buscar fórmulas que tornem compatíveis as vantagens da "diversidade cultural" com as vantagens das regras internacionais de comércio. Não há dúvida que a idéia da síntese das duas posições antagônicas é coerente como os interesses do Brasil. A conciliação dos interesses entre a posição norte-americana de que as regras multilaterais de comércio devem 
se aplicar aos produtos culturais nada mais são que mercadoria, e a defendida pela França e Canadá, de que os produtos culturais deveriam constituir exceção a essas regras, podem ser depuradas por um viés novo, que concilie os vários interesses.

Como disse Paulo Emílio Salles Gomes em seu ensaio clássico, no qual concilia a reflexão sobre o Brasil com a reflexão sobre os destinos do cinema brasileiro, "Cinema: Trajetória no Subdesenvolvimento": "Nada nos é estrangeiro, pois tudo o é". Como diria Chico Buarque na imaginária discussão entre ele e Caetano Veloso, criada pela imprensa à época do lançamento do movimento tropicalista: "nem só tamborim, nem só guitarra elétrica". A incorporação do nacional ao estrangeiro e vice-versa é parte da história da criação de muitas culturas, mas em particular e de forma profunda corresponde à essência da cultura brasileira, criada como fusão, em constante ebulição, de várias outras culturas. Essa caracterização da singularidade nacional projeta parâmetros nos quais se inscrevem a situação concreta do país e os interesses brasileiros na área cultural e comercial. $O$ pensamento brasileiro, que informa a diplomacia, incluindo a diplomacia cultural, segue este caminho de reconhecimento da aludida singularidade construída a partir do pluralismo e da independência conceitual. Traçado por uma tradição intelectuais esclarecidos como Mário de Andrade, Oswald de Andrade, Sérgio Buarque de Holanda, Antonio Candido, Augusto Meyer, Gilberto Freyre, Mário Pedrosa e Roberto Schwarz, entre outros que pensaram a "brasilidade" e, em particular, a inserção do Brasil no concerto internacional, o melhor da reflexão brasileira concebe o nacional na mão contrária do nacionalismo estreito e se propõe a incorporar e tensionar matrizes variadas do diálogo entre o nacional e o estrangeiro. Assim, "defesa da cultura nacional" ganha novo matiz pela franca incorporação das influências externas combinada hoje em dia com o desejo de exibir o que se produz no país em todos os mercados culturais globais.

A necessidade de conciliar o livre comércio com políticas públicas vem sendo gradualmente reconhecida. Com a aprovação da Convenção da UNESCO torna-se mais difícil antever negociações de comércio sem o devido cuidado com as questões levantadas pelo tema da Diversidade Cultural. Não é necessário renunciar in totum às negociações comerciais dos mercados culturais, desde que estas sejam feitas à luz dos conceitos acordados na Convenção da UNESCO e desde que os países membros se posicionem de forma a que as regras sejam usadas em favor dos 
objetivos do desenvolvimento. Os efeitos das regras multilaterais de comércio podem ser flexibilizados desde que seja dada real operacionalidade a dispositivos previstos no próprio GATS, tais como regras sobre subsídios, anti-dumping e salvaguardas, que constituem a chamada "Agenda Inacabada" do Acordo. O interesse de vários países, de preservar a liberdade de ação no setor cultural, principalmente no audiovisual, e seus temores de que a OMC não seja a organização mais apta a lidar com os temas culturais, deverão merecer enfoque conciliador, à luz da forte mensagem contida na Convenção aprovada na UNESCO.

A nova rodada de negociações, conhecida como a Rodada de Doha, terá que dar novo impulso às negociações que, como se sabe, têm sido extremamente difíceis. Assim como já não é mais concebível deixar de mencionar as preocupações com o meio-ambiente, torna-se cada vez mais necessário reconhecer os imperativos das políticas públicas para a promoção da diversidade cultural. Tendo em vista a preocupação com relação aos setores culturais explicitada tantas vezes pelos Estados, a OMC deverá achar formas que lhes dêem flexibilidade e segurança legal para adotar políticas de preservação e promoção cultural. A "Convenção sobre a Proteção e a Promoção das Expressões Culturais" aprovada na UNESCO, que imprime grande ênfase à cooperação e ao desenvolvimento, fornece um instrumento indispensável de legitimação da capacidade do Estado de fomentar os setores culturais, promover mercados mais isonômicos e padrões de desenvolvimento mais justos, favorecendo a reestruturação do sistema internacional em formato menos assimétrico e avançando em direção a uma cultura cívica global, centrada na redução do hiato entre nações ricas e pobres. 


\section{REFERÊNCIAS}

ALVIM NETO, Francisco Soares. Comunicação e Informação na UNESCO - A mídia como item da agenda internacional, um estudo sobre cooperação e confronto no multilateralismo de hoje. XXI CAE, 1990.

BARRAL, Welber (org.). O Brasil e a OMC. Curitiba: Juruá, 2002.

BENTES, Ivana. Cultura e Globalização na América Latina: globalização eletrônica. In: Globalização na América Latina: Integração Solidária. Brasília: Funag, 1997.

BRANT, Leonardo (org.). Diversidade Cultural, Globalização e culturas locais: dimensões, efeitos e perspectivas. São Paulo: Escrituras/Instituto Pensarte, 2005.

BRASIL. Lei 10.454, de 13 de maio de 2002. Brasília, 2002.

BRASIL. Medida Provisória no 2.228-1, de 6 de setembro de 2001. Brasília, 2001.

CASTELLS, Manuel. The Rise of The Network Society. Oxford: Blackwell Publishers, 2000.

CUÉLLAR, Javier Perez de (org.). Nossa Diversidade Criadora - Relatório da Comissão Mundial de Cultura e Desenvolvimento - UNESCO. Brasília:

Papirus/UNESCO, 1997.

EAGLETON, Terry. The Idea of Culture: UK: Oxford, 2000.

FARIAS, Eduardo da Costa. Difusão Cultural e Política Externa Brasileira: uma proposta de instrumentação, XXV CAE.

FEIGENBAUM, Harvey. Globalization and Cultural Diplomacy. The George Washington University, Center for Arts and Culture, 2001.

FRANÇA, Loi no 86-1067: relative à la liberté de Communication. França: Conseil Superieur de L'Audiovisuel, 1986.

FURTADO, Celso. Cultura e Desenvolvimento em Época de Crise. Rio de Janeiro: Editora Paz e Terra , 1984.

GAGNE, Gilbert et al. Les Récents Accords de Libre-Échange Conclus par les États-Unis: Une Menace a la Diversité Culturelle. Montreal : Centre Études Internationales et Mondialisation, 2004.

GEERTZ, C. The uses of Diversity. The Tanner Lectures on Human Values. The University of Michigan, 1985.

GRANTHAM, Bill. Some Big Bourgeois Brothel. Contexts for France's Culture Wars with Hollywood. UK: University of Luton Press, 2000.

GUIMARÃES, Samuel Pinheiro. Macunaíma: Subdesenvolvimento e Cultura.

Disponivel em: <www.desempregozero.com.br>

R. Inter. Interdisc. INTERthesis, Florianópolis, v.6, n.1, p. 254-278, jan./jul. 2009 
GUIMARÃES, Samuel Pinheiro. Quinhentos Anos de Periferia: uma contribuição ao estudo da política internacional. Porto Alegre /Rio de Janeiro:

UFRGS/Contraponto, 2000.

HEARTNEY, Eleanor. Pós-Modernismo. São Paulo: Cosac \& Naify, 2002.

HOLANDA, Sergio Buarque. Raízes do Brasil. Brasília: Editora Universidade de Brasília, 1963.

HUGHES, Robert. American Visions: The Epic History of Art in America. London: The Harvill Press, 1997.

HUNTINGTON, Samuel P. The Clash of Civilizations and the Remaking of World Order. New York: Simon \& Schuster, 1996.

INPC. Texto e relatório do Encontro de Ministros da Cultura. Cidade do Cabo: INPC, 2002.

JAMESON, Frederic. A Cultura do Dinheiro, ensaios sobre a globalização.

Petrópolis: Vozes, 2001.

LESSIG, Lawrence. Free Culture. How Big Media Uses Techonology and the Law to Lock Down Culture and Control Creativity. New York: The Penguin Press, 2004.

LÉVI-STRAUSS, Claude. The View From Afar. New York: Basic Books, 1985.

LÉVI-STRAUSS, Claude. Tristes Trópicos. São Paulo: Companhia das Letras,1996.

LIMA, Antônio A. Dayrell de. Porque uma Convenção sobre a proteção da Diversidade Cultural? Ensaio, 2004.

LIMA, Antonio Augusto Dayrell. O Conceito de Problemática Mundial e a Emergência de Formulações Políticas Globais nos ForosMmultilaterais: A perspetiva da Unesco.VII CAE, 1983.

MAYOR, Federico. Un Monde Nouveau. Paris: Unesco/ Edition Odile Jacob,1999.

MERLE, Marcel. Forces et Enjeux dans les Relations Internationales. Paris : Economica, 1985.

MOISÉS, J. A. Uma Nova Política para o Cinema Brasileiro. In: Cadernos Do Nosso Tempo. Rio de Janeiro: Ministério da Cultura do Brasil, 2001. n.4

MOISÉS, J.A., Diversidade Cultural e Desenvolvimento nas Américas: texto preparado para o Programa de Cultura da OEA, 2001.

OEI. Relatório do Grupo de Trabalho sobre Indústrias Culturais, Diversidade Cultural e Desenvolvimento Iberoamericano. Conferência LAS CULTURAS DE IBEROAMERICA EM EL SIGLO XXI, Organização dos Estados lberoamericanos. Rio de Janeiro, 2002. Anais... Rio de Janeiro, 2002.

R. Inter. Interdisc. INTERthesis, Florianópolis, v.6, n.1, p. 254-278, jan./jul. 2009 
PUTTMAN, D. The Undeclarad War - The struggle for the control f the world's film industry. London: Harper Collins Publishers, 1997.

RAGOSTA, John A. The Cultural Industries Exemptions from NAFTA, it's parameters.Canada-United States. Law Journal, v. 23, 1997.

REDE INTERNACIONAL DE POLÍTICAS CULTURAIS. Textos, comunicações, non-papers, documentação do Seminário sobre Diversidade Cultural em Vancouver. Paris: Halifax: 2002, 2003, 2004 e 2005.

REVISTA da Universidade de São Paulo. Revistausp: dossiê televisão. São Paulo: USP, 1994.

RIBEIRO, D. O Povo brasileiro- Formação e Sentido do Brasil. São Paulo: Cia. das Letras, 1995.

RIBEIRO, Edgard Telles. Diplomacia Cultural. Brasília: Fundação Alexandre de Gusmão, 1989.

RIGOURD, Serge. De l'exception à la diversité culturelle, La documentation française: Problèmes politiques e sociaux. Paris, 2004. n 904

RIGOURD, Serge. L’Exception Culturelle, coll. « Que sais-je ? ». Paris: Puf, 2002.

SANTOS, Milton. Por uma outra Globalização. Rio de Janeiro: Record , 2000.

SAV/MINC. O audiovisual e a Rodada do Milênio da Organização Mundial do Comércio - OMC. Brasília: Secretaria de Audiovisual do Ministério da Cultura do Brasil, 1999,

SOUZA-GOMES, João Carlos de, A Retirada Norte-Americana da UNESCO, no contexto dos principais aspectos da crise da Organização. XXI CAE,1990.

STIGLITZ, J. Globalization and its Discontents. New York: W.W.Norton \& Company, Inc., 2002.

TOMLINSON, J. Globalisation and Culture. Chicago: The University of Chicago Press, 1999.

TREBILCOCK, M; HOWSE, R. The Regulation Of International Trade. London: Routledge, 2002.

UNCTAD. Documentos e relatórios da Conferência sobre Serviços Audiovisuais. Genebra: UNCTAD, 2002.

UNESCO, Ante- Projeto de Convenção sobre a Proteção da Diversidade dos Conteúdos Culturais e Expressões Artísticas - UNESCO.

UNESCO. 2000-2010/ Diversité Culturelle: Les Enjeux du Marché. Paris : Rapport final de la Table Ronde de Ministres de la Culture, 2001. 
UNESCO. Declaração Universal sobre Diversidade Cultural. Paris: UNESCO, 2002.

UNESCO. Documentação das reuniões da Comissão de Cultura, no contexto da Conferência Geral, 2001, e das reuniões de expertos e reuniões intergovernamentais de exame do ante- projeto de Convenção, 2004 e 2005.

UNESCO. Informe Mundial sobre Cultura: diversidade cultural, conflito e pluralismo. São Paulo: Moderna, 2004.

UNESCO. Nossa Diversidade Criadora. São Paulo: UNESCO/Papirus, 1997.

VARIOS AUTORES, Diversité Culturelle e Mondialisation. Paris: Éditions Autrement, collection Mutations, 2004.

WTO. The Results of the Uruguay Round of Multilateral Trade Negotiations. Cambridge University Press, 1999.

Sítios da Internet consultados:

Coalition for Cultural Diversity - CCD www.cdc-cdc.org

Conferência das Nações Unidas sobre Comércio e Desenvolvimento - UNCTAD www.unctad.org

Groupe d'Etudes et de Recherches sur la Mondialisations - GERM www.mondialisation.org

Culturelink Network

www.culturelink.org

International Network for Cultural Diversity - INDC www.indc.net

Internationak Network on Cultural Policy - INCP www.incp-ripc.org

Movimento Internacional para o controle democrático dos mercados financeiros e suas instituições. ATTAC .

www.attac.org

Organização das Nações Unidas para a Educação, Ciência e Cultura - UNESCO www.unesco.org

United States Trade Representative -USTR www.ustr.gov

World Trade Organization - WTO

Ensaio:

Recebido em: 13/04/2009

Aceito em: 24/06/2009 www.wto.org 